\title{
MACHADO DE ASSIS: A CRÔNICA E A SELEÇÃO DA NOTÍCIA
}

\section{MACHADO DE ASSIS : THE CHRONICLE AND THE NEWS SELECTION}

MAGRI, Dirceu ${ }^{1}$

\begin{abstract}
RESUMO: Este estudo visa percorrer o fazer literário de Machado de Assis nas crônicas, da seleção da notícia à adaptação aos percalços da imprensa, haja vista o cronista ter vivenciado em plenitude o instante híbrido que marca a passagem da lentidão do livro para a velocidade da imprensa. Nesse período o jornal desenha uma nova forma, adequa-se ao fragmentário da diagramação da página, restringe o espaço e imprime noção de agilidade. A estas alterações subscreve-se um novo estilo de escrita que, embora contaminado pelo vestígio da ficção, irá suscitar movimento cada vez mais rápido, em resposta a um espírito que não mais se habitua à lentidão livresca e, aos poucos, ganha apreço pela velocidade contemporânea, feito o bonde, tão presente em suas crônicas.
\end{abstract}

PALAVRAS-CHAVE: Crônica, notícia, leitor, distanciamento, dúvida, ironia.

\begin{abstract}
This study aims to explore the Machado de Assis' literary composition in the chronicles from the news selection to adaptation to the mishaps of the press, as he experienced in fullness the hybrid moment that marks the passage from the slowness of the book to the speed of the press. In this period, the paper draws a new way, suits the fragmentary diagramming, restricts the space and prints notion of agility. These changes subscribes a new style of writing that, although contaminated by traces of fiction, will give rise to a faster and faster movement, in response to a spirit that no longer gets used to the bookish slowness and gradually gains appreciation for contemporary speed, as the tram, so present in his chronicles.
\end{abstract}

KEYWORDS: Chronicle, news, reader, estrangement, doubt, irony.

\footnotetext{
${ }^{1}$ Mestre e doutor pela Universidade de São Paulo, USP. Professor Visitante de Língua e Literatura Francesa na Universidade Federal de Viçosa, UFV.

Jangada | nr. 10, jul/dez, 2017 | ISSN 2317-4722 - 19 | Pá g i n a
} 
Ressaltar a fertilidade da produção machadiana dentro dos mais diversos gêneros - a poesia, a crítica, o teatro, o conto, o romance e a crônica -, tornou-se um lugar-comum crítico. Contudo, é nesta última que, ao longo de quarenta anos, Machado de Assis desenvolve sua escritura e toma domínio da expressão (GRANJA, 2000, pp. 15-30)², numa escrita em que a adequação das palavras resulta em uma economia narrativa, cuja proximidade ao interlocutor, capacita-o de uma imediata percepção do que o autor pretendera dizer. No diálogo com o leitor sobressai uma escrita ágil, sintética; nas entrelinhas, a apreciação, o concordar ou discordar - e a dúvida -, matéria-prima na constituição da ambiguidade presente na escrita machadiana.

Por sua vez, a crônica, à medida em que o jornal se desenvolve, abandona gradualmente seu tom ficcional e dá espaço a um matiz jornalístico, em consonância ao espírito reinante na época, marcado pela necessidade de informação. Havia certo cientificismo no ar e o progresso era perseguido a qualquer custo, como passaporte para o ingresso no concerto das nações ditas "civilizadas".

No Brasil do século XIX, mais que nas artes, é no jornal que essas preocupações ganham ressonância. Numa época de tensões sociais exacerbadas ao redor do mundo, por aqui pairavam sentimentos aprisionados, porém, latentes: a espera pela República não era algo tão distante, longínquo, estava às portas (BOSI, 2000, p 1).

O jornal surge então como válvula de escape, algo novo que entra em cena possibilitando uma democracia de ideias, uma república do pensamento, como afirma Machado:

O jornal é a verdadeira forma da república do pensamento. É a locomotiva intelectual em viagem para mundos desconhecidos, é a literatura comum, universal, altamente democrática, reproduzida todos os dias, levando em si a frescura das ideias e o fogo das convicções. (ASSIS, 1973, p. 945)

Novos ares trazem consigo novos questionamentos ou, no mínimo, uma readequação do anterior, do já existente. Em se tratando de jornais, escritores, cronistas etc., há de se observar que o contexto social e literário em que viviam, guardadas as devidas proporções, assemelhase ao atual. As oscilações sociais e econômicas só fizeram se acentuar com o fim do Império e

\footnotetext{
${ }^{2}$ Segundo a autora as crônicas teriam sido o "laboratório de ficção" de Machado e credita a elas o engenho que o autor exibiria em seus romances e contos.
}

Jangada | nr. 10, jul/dez, 2017 | ISSN 2317-4722 - 20 | Pá g in a 
início da República - veja-se, por exemplo, as recorrentes crônicas machadianas tratando do encilhamento e das inconstâncias do câmbio.

Editar livros no Brasil era coisa rara: as tiragens de autores brasileiros eram ínfimas em consonância à exiguidade de títulos e à escassez de leitores. Hélio de Seixas Guimarães em $O s$ leitores de Machado de Assis (2004, p. 47), ao discorrer sobre o público de literatura no século XIX, dimensiona a ideia aceita de que o público leitor consistia em grande parte de mocinhas e senhoras da elite e arrola José Veríssimo:

Ao fazer considerações sobre os pequenos círculos produtores e leitores de literatura, Veríssimo chama atenção para o pouco contato da produção literária com o público, atribuindo essa situação à ausência de uma "sociedade" e também às distâncias e dificuldades de comunicação no país.

Para relativizar a crença generalizada de que havia um imenso leitorado feminino no Brasil, Veríssimo lembra que "nossas avós, na máxima parte, não sabiam ler" (VERÍSSIMO, 1977, pp. 31-48) e que, em 1890, apenas 16 ou 17 em cem habitantes do país estavam aptos à leitura.

Considerando-se que na passagem do século XIX para o XX apenas 18\% da população eram alfabetizados e aptos a ler livros apenas uns $2 \%$, é possível desenhar o contexto no qual esses jovens literatos estavam inseridos. A carência de leitores, aliada às dificuldades financeiras que impediam o pleno desenvolvimento do mercado editorial, impele os jovens escritores a migrarem ${ }^{3}$ da forma perene do livro para a fugaz folha de jornal, de público infinitamente maior. Afora isso, a atividade jornalística rendia reconhecimento público e político. Em 1903, Olavo Bilac comenta tal trânsito:

Hoje, não há jornal que não esteja aberto à atividade dos moços. O talento já não fica à porta, de chapéu na mão, triste e encolhido, farrapão e vexado, como o mendigo que nem sabe como há de pedir a esmola. A minha geração, se não teve outro mérito, teve este, que não foi pequeno: desbravou o caminho, fez da imprensa literária uma profissão remunerada, impôs o trabalho. Antes de nós, Alencar, Macedo e todos os que traziam a literatura para o jornalismo, eram apenas tolerados: só a política e o comércio tinham consideração e

\footnotetext{
${ }^{3}$ De fato, a grande maioria sequer havia publicado livros antes de adentrarem os jornais.
} 


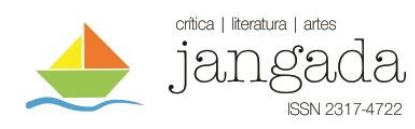

virtude. Hoje, oh! espanto! Já há jornais que pagam versos! (BILAC, 1996, p. 56)

Machado de Assis vivenciou em sua plenitude esse instante híbrido que marca a transposição da lentidão do livro à velocidade da imprensa, em que o jornal desenha uma nova forma, adequa-se ao fragmentário da diagramação da página, restringe o espaço (ASSIS, 1957, p. 278 , vol. 22$)^{4}$ e imprime noção de agilidade.

A essas alterações subscreve-se um novo estilo de escrita que, embora contaminado pela ficção, irá suscitar movimento cada vez mais rápido em resposta a um espírito que não mais se habitua à lentidão livresca, mas, aos poucos, ganha apreço por certo laconismo, algo visto como insígnia de desenvolvimento e progresso, portanto, contemporâneo - a exemplo da locomotiva.

É neste gênero ágil, fugaz e à la minute, que Machado vai exercitar seu tom combativo e analítico, antecipando questões que ainda soam atuais, tal sua perspicácia em captar o circunstancial e lançá-lo para além do seu tempo, preservando-o na memória.

Desse modo, sob a pena de Machado, evidencia-se a excelência de um gênero que possibilita não só captar o espírito na fugacidade do circunstancial, preservando-o, mas também oferece subterfúgios no espaço do texto para que o cronista lance questões para além do efêmero do fato, desorganizando o ulterior num lance puramente textual.

O fato, preservado no âmbito textual, atualiza o leitor moderno sobre hábitos e a origem de características de nossa sociedade que, parece, sempre nos acompanharam. Com isso, tornase possível traçar um painel que não só constrói um panorama social da época em que a crônica foi escrita, mas, para o leitor moderno, surge como importante registro para o entendimento de condutas e procedimentos - de antes e de hoje. A título de exemplificação, eis Machado:

Cai-me agora debaixo dos olhos o expediente do ministério do Império, publicado ontem na folha oficial.

\footnotetext{
${ }^{4}$ Em uma das crônicas da Semana Ilustrada (x/5/1864), o cronista afirma: "Leitores, é assim, não somos nada diante do paginador." (MACHADO DE ASSIS, 1957, p. 278, vol. 22) *Embora essas crônicas tenham sido creditadas a Machado de Assis na publicação da Editora Jackson, posteriormente, elas foram excluídas na Obra completa da Aguilar. Magalhães Jr., em Machado de Assis desconhecido (1957, pp. 210-222) comenta sobretudo as "Preleções Gramaticais" inseridas nas "Crônicas do Dr. Semana" e atribuídas a Machado, algo que, a seu ver, soava bastante leviano, pois em nada condizem com o feitio intelectual do escritor. Machado, porém, no Diário do Rio de Janeiro, em 10/11/1864 (Vol. 23. 1957, p. 44), afirma: "Tenho limitado as proporções deste folhetim pelas causas já apontadas no começo, e por outra, que é a falta de espaço.”
}

Jangada | nr. 10, jul/dez, 2017 | ISSN 2317-4722 - 22 | P á g i n a 


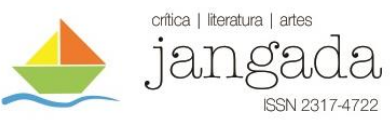

Vejo ali que o respectivo ministro oficia ao seu colega da Fazenda, “declarando que o conselheiro Cândido Borges Monteiro, jubilado em uma das cadeiras da Faculdade de Medicina desta cidade, tem direito ao ordenado por inteiro, por ter mais de 25 anos de serviço efetivo".

Parece estranho isto. A que se pôs dúvida em fazer efetiva a determinação dos respectivos estatutos. Não consta, porém, que o tesouro caísse em equívoco aritmético. (...)

Não falta quem dê à língua e diga que o lente, a que se refere o ofício do Sr. Ministro do Império, tendo sido aposentado antes da abertura das câmaras, não completou os 25 anos, que só se terminaram depois de fechado o parlamento. (ASSIS, 1957, pp. 113-114, vol. 22)

Numa espécie de jogo ficcional com o leitor, o cronista é marcadamente crítico, e para isso tece uma escritura de estrutura acentuadamente dialógica, uma conversa com seu leitor, que supõe já estar a par dos acontecimentos e que, agora, degustará de seus comentários um tanto irônicos. Nisso reside a busca de uma elocução literária que se sobrepõe ao empirismo do fato, relativizando-o enquanto notícia.

Tal conceito operatório de escrita, que abranda a crueza transparente da notícia, demonstra a capciosidade de Machado ao se servir da notícia: se por um lado privilegia o literário em consonância com seu mundo de romancista e voraz leitor de grandes obras, por outro, vai de encontro à escrita dita jornalística, que se situa na fronteira limítrofe entre a mercadoria e a arte - o jornal e o livro -, e aí a crônica torna-se exemplo eletivo.

Uma vez que em Machado a crônica é comumente construída a partir de dados já conhecidos de seu público, os fatos são apresentados por viés diferente, valorizados a partir de ângulos específicos e, sobretudo, revestidos de certo viço, tudo para caracterizá-los como novidade, notícia fresca. Neste jogo ficcional cujo intuito maior é atrair a atenção do leitor, Machado às vezes se ressente do determinismo que condiciona a crônica a tratar do passado, daquilo que já não traz em si nada de novidadeiro, e dispara:

Tal era a reflexão que eu fazia comigo, quando me trouxeram os jornais. Que me diriam eles que não fosse velho? A guerra é velha, quase tão velha quanto

\footnotetext{
${ }^{5}$ Diário do Rio de Janeiro, Comentários da Semana, 7/1/1862.
}

Jangada | nr. 10, jul/dez, 2017 | ISSN 2317-4722 - 23 | Pá g in a 


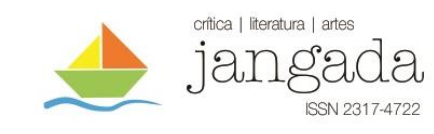

a paz. Os próprios diários são decrépitos. A primeira crônica do mundo é justamente a que conta a primeira semana dele, dia por dia, até o sétimo em que o Senhor descansou. O meu velho colega bíblico omite a causa do descanso divino; podemos supor que não foi outra senão o sentimento da caducidade da obra. (ASSIS, 1957, p. 429, vol. 26). ${ }^{6}$

Embora produzisse uma crônica revestida de verniz literário, isso não bastava por si só; era preciso então tratar a notícia de forma que, mesmo após o lustro ficcional, ela ainda trouxesse indícios do novo e do desconhecido. Para isso Machado inova em sua escritura jornalística e desenvolve aquilo que mais tarde se chamaria "pirâmide invertida"7, isto é, destina o primeiro parágrafo da crônica aos fatos mais importantes, mais atrativos, os alicerces da notícia.

De fato, na técnica em si nada há de inovador, uma vez que remonta às origens do gênero, precedendo mesmo a crônica, cujo esteio dá-se no coloquial, no recontar o fato ocorrido, tal qual Machado observa:

Não posso dizer positivamente em que ano nasceu a crônica; mas há toda a probabilidade de crer que foi coetânea das primeiras duas vizinhas. Essas vizinhas, entre o jantar e a merenda, sentaram-se à porta, para debicar os sucessos do dia. Provavelmente começaram a lastimar-se do calor. Uma dizia que não pudera comer ao jantar, outra que tinha a camisa mais ensopada do que as ervas que comera. Passar das ervas às plantações do morador fronteiro, e logo às tropelias amatórias do dito morador, e ao resto, era a cousa mais fácil, natural e possível do mundo. Eis a origem da crônica. (ASSIS, 1957, p. 283 , vol. 24$)^{8}$

Nessas ligações mantidas pela crônica com o coloquial, ao recontar sua história o narrador particulariza o que considera ter maior poder de atração, o lance que por sua magnitude prenderá o leitor, além, é claro, de usá-lo como 'gancho’ para o que vem a seguir.

\footnotetext{
${ }^{6}$ Gazeta de Notícias, A Semana, 26/11/1893.

${ }^{7}$ Técnica de estruturação do texto jornalístico, cuja origem, acredita-se, tenha sido por volta de 1861 na imprensa nova-iorquina.

${ }^{8}$ Ilustração Brasileira, História de quinze dias, 1/11/1877.
} 




Nessa "conversa fiada", logo após os acontecimentos mais importantes, Machado dispõe comentários particularmente ambíguos, que despertam e instalam em seu leitor a dúvida. Esta comumente provém do inusitado do fato, que, não raro, faz com que o leitor questione sua veracidade, porém, nota-se que é justamente a partir do detalhe curioso - para não dizer esdrúxulo -, da notícia que o cronista inicia com o leitor um diálogo marcado pela dubiedade.

Aos poucos, num jogo de sedução, acerca-se dele convencendo-o de que o que acabara de ler não era exatamente o que parecia. De pronto, cria-se uma relação dialógica entre narrador e leitor, por meio de uma "narrativa" que privilegia aspectos precisos do fato, expandindo-os, e fazendo deles o mote da crônica. Uma vez o leitor convencido de que o que lera à primeira vista é no mínimo duvidoso, o diálogo desenvolve-se em um plano mais distante e secundário: não se trata mais de convencer seu leitor a correr os olhos até o final da crônica, mas, agora, é importante que esse leitor desconfie com ele, o narrador.

Desse modo, uma dúvida que já fora do narrador passa a habitar o espírito do leitor, enredando-o em uma teia de ambiguidades e desconfiança. Para isso o narrador se distancia, coloca-se fora da notícia e iguala-se ao leitor abandonando a superioridade característica de um narrador onisciente. Nesse processo, ambos têm agora as mesmas dúvidas e se irmanam nelas. Vale lembrar que embora compartilhem das mesmas suspeitas e ceticismos, o cronista não abandona de todo sua proeminência sobre o leitor, mantendo, ainda que de maneira velada, a contundência da crítica.

Nessa sua estilística, o cronista recorre à memória e à diacronia e "elabora uma linguagem de distanciamento pela qual o sujeito se põe e se declara existencialmente alheio à conjuntura que tinha virado manchete em todos os jornais do país. O objeto próximo da história contemporânea é recortado, mencionado, mas posto fora do círculo do "eu"' (BOSI, 2000, p. 8). Exemplo significativo dessa praxe é a antológica crônica "O velho Senado" publicada na Revista Brasileira de junho de 1898.

Ainda nessa lógica do olhar de fora, Machado recorre ao boato: "Não falta quem dê à língua e diga que o lente, a que se refere o ofício do Sr. Ministro do Império,...” (ASSIS, 1957, pp. 113-114, vol. 22) $)^{9}$ e mais: “A notícia, boato, ou o que quer que seja...” (ASSIS, 1961, p. 129 , vol. 28) ${ }^{10}$, imprimindo assim a ideia de que não está imiscuído nos acontecimentos e - o que é mais importante - , a de que seus comentários, ainda que marcados por certa dose de

\footnotetext{
${ }^{9}$ Diário do Rio de Janeiro, Comentários da Semana, 7/1/1862.

${ }^{10}$ Gazeta de Notícias, A Semana, 15/3/1896.
} 
parcialidade, são pautados por preceitos éticos aceitos e corroborados pela esmagadora maioria da sociedade.

Ele, narrador, nada mais seria que um mero contador de histórias que se obriga a transmiti-las da maneira mais transparente possível, embora incapaz de total isenção crítica. A construção de uma opinião estaria relacionada não mais à realidade, que pode ser apreendida pelo espelho da visão, mas sim pela distância da análise. Embora tenha se igualado ao leitor, nessa elocução do distanciamento, o narrador revela mais uma vez que não o fez de todo, fato é que mantém a crítica difusa em seus comentários.

Ora, tal mecanismo de escrita trabalha em oposição à noção da crônica como espelho de uma realidade (a notícia), uma vez que o circunstancial flagrado por Machado vem despido de sua crueza e aridez, no entanto, esse "literaturizar" o fato não implica abandono de reflexão, sobretudo porque esta é suscitada por meio da dúvida lançada pelo narrador.

Afirmar que Machado se distancia para analisar, pensar e refletir, é o mesmo que dizer que, de certa maneira, ele não se envolve, não toma qualquer parti pris e, se opina e critica, o faz com acertada racionalidade. Nesta lógica, conclui-se que também inovou ao engendrar o distanciamento como mecanismo de escrita nas crônicas, artifício que apareceria bem mais tarde nas artes cênicas sob o nome de distanciamento crítico $^{11}$, em oposição ao processo catártico, esse remédio da alma teorizado por Aristóteles na Poética, responsável por purgar as emoções.

Voltando à feitura da crônica "conversa-fiada", convém lembrar que nesse processo de escritura jornalística o que primeiro se apresenta ao cronista é o recorte da notícia, a seleção do mais importante face à profusão de fatos, e aí Machado argumenta:

Os acontecimentos parecem-se com os homens. São melindrosos, ambiciosos, impacientes, o mais pífio quer aparecer antes do mais idôneo, atropelam tudo, sem justiça nem modéstia... E quando todos são graves? Então é que é ver um miserável cronista, sem saber em qual pegue primeiro. Se vai ao que lhe parece mais grave de todos, ouve clamar outro que lhe não parece menos grave, e hesita, escolhe, torna a escolher, larga, pega, começa e recomeça, acaba e não acaba... (ASSIS, 1957, pp. 179-181, vol. 26) ${ }^{12}$

\footnotetext{
11 Refiro-me aqui ao teatro de Bertold Brecht (1898-1956) e o V-Effekt ou efeito V (do alemão Verfremdungseffekt), que também pode ser traduzido por "efeito de estranhamento", "efeito de distanciamento" ou mesmo "efeito de desilusão".

${ }^{12}$ Gazeta de Notícias, A Semana, 4/12/1892.
}

Jangada | nr. 10, jul/dez, 2017 | ISSN 2317-4722 - 26 | Pá g i n a 
E, em meio à indecisão em escolher qual fato será dotado da prerrogativa de distinção, discorre:

Felizes os povos que escrevem por linhas verticais! Podem arranjar as crônicas de maneira que os acontecimentos fiquem sempre em cima; a parte inferior das linhas cabe às considerações de menor monta, ou absolutamente estranhas. Moralmente, é assim que escrevo. ${ }^{13}$

Nesse sentido, na feitura da crônica jaz implícita a preocupação do cronista com um leitor ocupado que, caso não fosse fisgado no primeiro instante, mudaria de página, sem sequer terminar o parágrafo. Pensando nesse leitor ágil, cioso de saber de tudo um pouco, Machado percorre vários assuntos, e neste ziguezaguear desenha metáforas, tinge-as de fino humor e ironia, dissolve a tinta em uma profusão de citações, adensa o matiz com adjetivação insólita, escorrega para a paródia, brinca e suaviza a notícia. Não bastasse isso, atenta para a lentidão da notícia face à velocidade do tempo e declara:

A mesma coisa acontece ao leitor, com a diferença que ele faz ou não faz nada se quer, e eu hei de pegar do papel e da tinta, e escrever para aí alguma coisa, tenha ou não vontade e assunto.

Vontade já se vê que não. Assunto ainda menos; [...]. Já lá se vão sete ou oito dias; creio que é uma boa idade para qualquer negócio que se respeite, recolher-se a bastidores, e dar lugar a outros. (ASSIS, 1957, p. 272) ${ }^{14}$

Habituado à intensa agilidade dos atuais meios de comunicação, talvez o leitor contemporâneo não considere a morosidade da notícia como fator tão preponderante, entretanto, não era só isso que "perturbava" o espírito do cronista: Machado também se ressente da ausência de fatos novos e do vagar das notícias, algo que o leva, nos instantes que antecedem à escrita, provar da angústia da folha em branco:

\footnotetext{
${ }^{13}$ Gazeta de Notícias, A Semana, 4/12/1892.

${ }^{14}$ Gazeta de Notícias, Balas de Estalo, 26/10/1885.
}

Jangada | nr. 10, jul/dez, 2017 | ISSN 2317-4722 - 27 | Pá g in a 


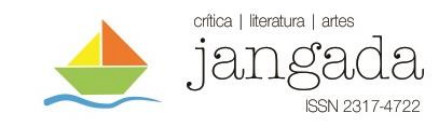

Assim, mil fantasias de ordem poética atravessaram o meu espírito, e eu estava longe de pensar nas tiras de papel almaço que tenho agora diante de mim, e que espero enchê-las ao acaso - se Deus quiser. (ASSIS, 1957, p. 58, vol. 23) ) $^{15}$

Diante da efemeridade do jornal nem sempre os fatos são animadores; o vagar e a flutuação na chegada de notícias é algo insidioso, fazendo com que Machado classifique as semanas em pobres e ricas, exprimindo-se com evidente ironia:

Que boas que são as semanas pobres! As semanas ricas são ruidosas e enfeitadas, aborrecíveis, em suma. Uma semana pobre chega à porta do gabinete, humilde e medrosa:

_ Meu caro senhor, eu pouco tenho que lhe dar. Trago as algibeiras vazias; quando muito, tenho aqui esta cabeça quebrada, a cabeça do Matias...

_ Mas que quero eu mais, minha amiga? Uma cabeça é um mundo... Matias, que Matias?

_ Matias, o leiloeiro que passava ontem pela rua de S. José, escorregou e caiu... Foi uma casca de banana.

__ Mas há cascas de banana na rua S. José?

$[\ldots]$

Mas as semanas ricas! Uma semana como esta que ontem acabou, farta de sucessos, de aventuras, de palavras, uma semana em que até o câmbio começou a esticar o pescoço pode ser boa para quem gosta de bulha e de acontecimentos. Para mim que amo o sossego e a paz é a pior de todas as visitas.

Não há tempo para fazer estilo com elas, nem abrir portas à imaginação. Todo ele é pouco para acudir os fatos. (ASSIS, 1957, pp. 181-186, vol. 27) ${ }^{16}$

Ora, nessa alegoria em que a senhora entregadora de notícias, inconstante, ora nada tem a dizer, ora vem abarrotada de novidades, Machado mais uma vez apela para a ironia para se furtar da angústia que precede a escolha dos assuntos mais importantes ao compor sua "pirâmide invertida", ainda que exiba habilidade em tratar dos problemas diários. Esse

${ }^{15}$ Diário do Rio de Janeiro, Ao Acaso, 25/7/1864.

${ }^{16}$ Gazeta de Notícias, A Semana, 16/9/1894.

Jangada | nr. 10, jul/dez, 2017 | ISSN 2317-4722 - 28 | Pá g i na 


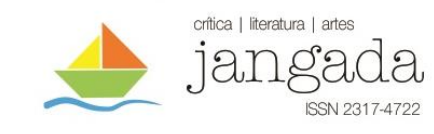

momento que precede a escrita torna-se então parte de um ritual, no qual o esforço não resulta propriamente da dificuldade de escrever, mas sim da escolha, da seleção. Entretanto, apesar da pausa inicial, Machado mantinha ritmo ágil em correspondência à velocidade do jornal. JeanMichel Massa comenta: "Escreveu crônicas, ao que parece, bastante rapidamente e ao correr da pena. Uma delas terminava por esta confidência: "Vou rever o que escrevi.,"

E acrescenta:

Sem esforço aparente, Machado de Assis deixava fluir a verve e a facilidade natural de sua pena surgia quando ele tratava de problemas de todos os dias. Convergia naturalmente para a expressão e descobria as referências ou as citações que convinham. Já se disse o quanto a prática cotidiana do ofício de jornalista facilitou a tarefa do futuro romancista. (MASSA, 1971, p. 462)

Assim, na falta de um acontecimento vultoso a dizer, Machado comumente não hesita em lançar mão do prosaico e iça da multidão, tal no exemplo acima, o ilustre e desconhecido leiloeiro Matias, que quebrara a cabeça ao escorregar em uma casca de banana. Ora, se em uma semana pobre, o apelo que se faz é ao pitoresco, nas semanas ricas, o cronista deve se conter e não apelar ao puro sensacionalismo, prática que condena. Em crônica publicada em 14/3/1885, nas Balas de Estalo, Machado já sinaliza um dos efeitos dessa prática, e que se tornaria comum: a "glamourização" da violência e da criminalidade, ao discorrer sobre a capoeiragem, condenada no Rio de Janeiro de então:

Capoeira é homem. Um dos característicos do homem é viver com o seu tempo. Ora, o nosso tempo (nosso e do capoeira) padece de uma coisa que poderemos chamar - erotismo da publicidade. (...) [O capoeira] recolhe à navalha, espalha facadas, certo de que os jornais darão notícias das suas façanhas e divulgarão seus nomes.

Diante de tal prática, vaticina:

Já o leitor adivinhou o meu medicamento. (...) Sim, senhor, adivinhou, é isso mesmo: não publicar mais nada, trancar a imprensa às valentias da capoeiragem. Uma vez que não dê mais notícia, eles se recolhem às tendas,

Jangada | nr. 10, jul/dez, 2017 | ISSN 2317-4722 - 29 | Pág in a 


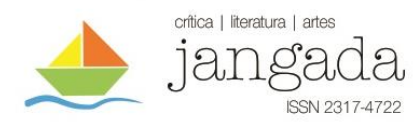

aborrecidos de ver que a crítica não anima os operosos. (ASSIS, 1957, pp. 217-218, vol. 25)

Embora critique o sensacionalismo na imprensa, Machado se vê às voltas com o dilema de todo cronista: atrair e conquistar a atenção do leitor. Entretanto, se as semanas pobres dão margem ao prosaico, as semanas ricas, férteis em notícias, são uma tentação para o cronista, pois oferecem vasto material de cunho sensacionalista. Machado não se furta às tragédias, sabe que deve informá-las ao público, no entanto, o faz de maneira a poupá-lo, relatando o trágico de modo a enaltecer os aspectos emocionais da notícia, com a crônica operando como veículo catalisador das emoções reprimidas e obscuras do leitor. Nessa lógica, o sensacional opera como agente catártico das instâncias psíquicas.

Neste jogo ficcional, o leitor é preservado e, mais uma vez pela técnica do distanciamento, leitor e narrador se ausentam do fato em si, para observá-lo de lugar seguro. Em crônica já citada (16/9/1894), em que a semana rica, alcoviteira, traz-lhe uma quantidade avassaladora de notícias, é possível deslindar tal mecanismo de escrita. Ora, tão volumosa é a quantidade de notícias que a semana rica não consegue transportar sozinha, precisa de carruagem e lacaio: aqui, tem-se um primeiro distanciamento. A emoção do estar presente, do participar, enfim, do viver o fato, perde o impacto quando este é recontado por um terceiro. $\mathrm{O}$ narrador, que está recontando a história ao leitor, já nem mais é aquele que a ouviu direto da fonte. Pode ser que a semana rica - senhora alcoviteira -, tenha ouvido a notícia recontada por outro alguém; é neste ponto que o sensacionalismo pode ter ação expansiva, distorcendo e mesmo aumentando os fatos.

Observe na sequência da crônica de 16/9/1894 e a técnica aplicada:

(...) o edifício da Fábrica das Chitas que afinal recebeu o último piparote do tempo e caiu. Pelo resultado, podemos dizer que foi o dedo da Providência que o deitou abaixo; não matou ninguém. Imagine se o bonde que descia passasse no momento de cair o monstro, e que o homem que queria ir ver na casa arruinada a cadela que dava leite aos filhos houvesse chegado no lugar onde estavam os cães. Que desastre, santo Deus! que terrível desastre!

_ Terrível, minha senhora? Não nego que fosse feio, mas o mal seria muito menor que o bem. Perdão; não gesticule antes de ouvir até o fim...

Jangada | nr. 10, jul/dez, 2017 | ISSN 2317-4722 - 30 | Pá g in a 


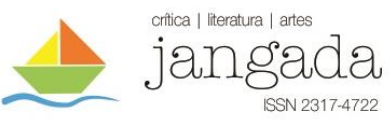

Repito que o bem compensaria o mal. Imagine que morria muita gente, havia pernas esmigalhadas, ventres estripados, crânios arrebentados, lágrimas, gritos, viúvas, órfãos, angústias, desesperos...

Era triste, mas que comoção pública! que assunto fértil para três dias!

Recorde-se da Mortona.

_ Que Mortona?

_ Creio que houve um desastre deste nome; não me lembro muito bem, mas foi negócio de três dias. Nós precisamos de comoções públicas, são os banhos elétricos da cidade. Como duram pouco, devem ser fortes. (ASSIS, 1957, pp. 181-186, vol. 27) $)^{17}$

À notícia do desmoronamento trágico da Fábrica das Chitas, contudo, sem vítimas e recontado pela senhora semana rica, nosso cronista, além do distanciamento, pois aí se tem um recontar do fato já carregado das impressões daquela, acrescenta a ironia, artifício de ação certeira que responde a dois objetivos: despertar a reflexão por parte do leitor e diluir o sensacionalismo. Aqui, Machado dispensa uns piparotes ao leitor, ao ironizar a senhora semana rica que exagera na tintura dos fatos - há aí o esgotamento da vida, a morte, a perda, a separação. Nosso autor, em réplica, lança como hipótese história mais sangrenta ainda, elevando em potência o horror da notícia: a carnificina deixa o reino dos animais e passa para o reino dos humanos, adquirindo caráter dantesco.

Assim, lembra ao leitor de que ele também tem sua parcela de contribuição na propagação da notícia sensacionalista. Logo, porém, tranquiliza-o, colocando-o em lugar seguro ao se distanciar no tempo, em algo que se perdeu, e mais uma vez a ironia se faz presente ao relembrar as necessidades gerais de todos, as "comoções públicas", mecanismo de extrema importância na suavização do sensacionalismo. Assim, desenvolveu Machado o inusitado desmoronamento da tal Fábrica das Chitas.

Por fim, vale reiterar que também a ironia tem alta importância nas crônicas machadianas, atuando ora como mecanismo de distanciamento - instigador da análise e reflexão -, ora como elemento de provocação, reprovação, capaz de engendrar a dúvida. Sobre isto, comenta J. M. Massa (1971, pp. 469, 473, 525): “A arma empregada pelo combatente era geralmente a ironia fustigante, (...) que atacava e ridicularizava". E acrescenta: "A ironia era a

${ }^{17}$ Gazeta de Notícias, A Semana, 16/9/1894.

Jangada | nr. 10, jul/dez, 2017 | ISSN 2317-4722 - 31 | Pá g i na 


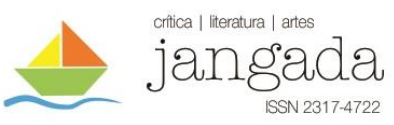

arma favorita do jornalista, mas seus propósitos amáveis não excluíam a reprovação direta (...)" E completa: "Entre o sério e a ironia, insere-se a ambiguidade, esta arma de dois gumes, para fustigar a consciência."

Desse modo, da notícia à crônica, Machado trabalha a escrita de modo a fazê-la não só instrumento de expressão, mas veículo de combatividade e crítica.

\section{REFERÊNCIA BIBLIOGRÁFICAS}

ASSIS, Machado de. O Jornal e o livro. Correio Mercantil, Rio de Janeiro, 10 e 12 jan. 1859. In: Obras Completas. Vol. III. Rio de Janeiro: Editora Nova Aguilar, 1973. Pontos e Vírgulas, (x)/5/1864, Semana Ilustrada. In: Crônicas. Vol. 22. Rio de Janeiro: W.M. Jackson Inc. Editores, 1957.

. Crônicas. Vol. 23. Rio de Janeiro: W.M. Jackson Inc. Editores, 1957. Crônicas. Vol. 24. Rio de Janeiro: W.M. Jackson Inc. Editores, 1957. . Crônicas. Vol. 25. Rio de Janeiro: W.M. Jackson Inc. Editores, 1957. . A Semana. Vol. 26. Rio de Janeiro: W.M. Jackson Inc. Editores, 1957. . A Semana. Vol. 27. Rio de Janeiro: W.M. Jackson Inc. Editores, 1957. . A Semana. Vol. 28. Rio de Janeiro: W.M. Jackson Inc. Editores, 1961.

BILAC, Olavo. Vossa insolência: crônicas. Organização: Antônio Dimas. Vol. VI. Coleção Retratos do Brasil. São Paulo: Companhia das Letras, 1996.

BOSI, Alfredo. O teatro político nas crônicas de Machado de Assis. Coleção Documentos. Revista No. 1, Instituto de Estudos Avançados. São Paulo: Universidade de São Paulo, Fevereiro/2000.

GRANJA, Lucia. "Introdução geral à crônica de Machado de Assis". In: Machado de Assis, escritor em formação: à roda dos jornais. Campinas: Mercado das Letras; São Paulo: Fapesp, 2000.

GUIMARÃES, Hélio de Seixas. Os leitores de Machado de Assis: o romance machadiano e o público de literatura do século 19. São Paulo: Nankin Editorial; Editora da Universidade de São Paulo.

MAGALHÃES JR. Machado de Assis desconhecido. Rio de Janeiro: Editôra Civilização Brasileira, 1957.

MASSA, Jean-Michel. A Juventude de Machado de Assis. Rio de Janeiro: Editôra Civilização Brasileira, 1971.

VERÍSSIMO, José. Das condições da produção literária no Brasil. In: Estudos de Literatura Brasileira ( $3^{\text {a }}$ série. Belo Horizonte: Editora Itatiaia; São Paulo: Editora da Universidade de São Paulo, 1977.

Jangada | nr. 10, jul/dez, 2017 | ISSN 2317-4722 - 32 | Pá g in a 